\title{
ASPECTOS DE PROCESSOS NECESSÁRIOS E PRINCÍPIOS GERATIVOS NA ANÁLISE DO VIVENTE EM ARISTÓTELES
}

\section{ASPECTS OF NECESSARY PROCESSES AND GENERATING PRINCIPLES IN THE ANALYSIS OF THE ALIVE BEINGS IN ARISTÓTELES}

\author{
Rodrigo Romão de Carvalho ${ }^{1}$
}

Recebido em: 01/2019

Aprovado em: 05/2019

\begin{abstract}
Resumo:Neste artigo, procurarei tecer uma linha argumentativa a partir da qual se desenvolve um exame sobre certos aspectos processuais de caráter naturalmente necessários e sobre certos princípios gerativos, que Aristóteles lançaria mão para desesenvolver a sua investigação concernente à natureza composicional dos organismos vivos. Para tanto, procederei no sentido de, em primeiro lugar, discernir a respeito das várias formas através das quais o sentido de necessidade poderia ser analisado, no âmbito do estudo acerca da especificidade estrutural e constituinte que os seres vivos poderiam ser, adequadamente, examinados. E, em segundo lugar, pretenderei relacionar estas formas ou estes aspectos de entender a nessecidade natural - como fatores explanatórios da composição orgânica -, com os modos em função dos quais Aristóteles compreenderia os fundamentos dos processos gerativos, relativamente ao domínio do vivente. Com isto, espero contribuir de algum modo com uma elucidação de caráter geral quanto a seguinte questão: em que medida os seres vivos, de acordo com a concepção aristotélica de natureza, preserva-se-iam como tais, isto é, como um tipo de existência ôntica singular na realidade natural?
\end{abstract}

Palavras-chave: Hilemorfismo. Necessidade hipotética. Necessidade absoluta. Necessidade geométrica. Geração orgânica.

\begin{abstract}
In this paper, I'll try to make an argumentative line from which an examination is made of certain procedural aspects of naturally necessary character, and about certain generative principles that Aristotle would to make use to develop his research, concerning the compositional nature of living organisms. In order to do so, I shall proceed first to discern the various ways in which the sense of necessity could be analyzed in the context of the study of the structural and constitutive specificity that living beings could properly be examined. And, secondly, I'll try to relate these forms or these aspects of understanding the natural necessity - as explanatory factors of organic composition -, with the ways in which Aristotle would understand the foundations of the generative processes, relative to the domain of the living. With this, I hope to contribute in some way to an elucidation of general character as to the following question: to what extent living beings, according to the Aristotelian conception of nature, preserve themselves as such, that is, as a kind of singular ontic existence, in the natural reality?
\end{abstract}

Keywords: Hylemorphism. Hypothetical necessity. Absolute necessity. Geometric necessity. Organic generation.

\footnotetext{
${ }^{1}$ Graduação, Mestrado e Doutorado pela USP.
} 


\section{Introdução}

Em Aristóteles, o conhecimento relativo ao domínio dos seres vivos baseia-se, conforme o hilemorfismo (de hyle (matéria) + morphe (forma)) como um padrão de racionalidade científica, na descrição dos processos através dos quais a forma do animal regula os movimentos absolutamente necessários da matéria elementar, a fim de promover a realização de diversas atividades vitais. Aquilo que Aristóteles designa por ananke ex hupotheseos, isto é, necessidade sob hipótese, ou, simplesmente, necessidade hipotética, diz respeito justamente a tais processos.

Apartir da intervenção de um princípio anterior assumido como hipótese - por exemplo, de um homem (princípio) há de ser gerado (hipótese) outro especificamente idêntico - , o qual corresponde à forma do animal, o curso espontâneo dos movimentos absolutamente necessários da matéria elementar, decorrente das propriedades essenciais dos elementos, é desviado, de modo a ajustá-lo às circunstâncias nas quais se estabelecem determinadas misturas (por exemplo, carne, ossos, tendões), que são requisitadas pela composição orgânica.Oselementos,nestasmisturas,adquirem,então,propriedadesacidentais que são condições necessárias para que o ser vivo seja capaz de realizar as suas atividades características, ou seja, as funções vitais, dentre as quais a mais natural corresponte aoato gerativo ou reprodutivo, que consiste noengendramento constantemente da compleição orgânica (ARISTÓTELES, De Anima, II.4, 415a23-29).

\section{Processos Necessários}

\section{Necessidade hipotética}

A fim de que o animal seja capaz de executar as funções pelas quais ele vem a ser o que é, e definido enquanto tal, é necessária a emergência de certas propriedades, que só pode ser explicada mediante uma causalidade teleológica envolvida no processo de constituição do vivente, pois não seria possível que, a partir tão somente das interações espontâneas entre os elementos, sobreviesse os devidos arranjos composicionais, pelos quais se estabelece a complexa rede de estruturas que o organismo comporta: eis no que consiste, fundamentalmente, a necessidade ex hupotheseos no exame dos seres vivos. Neste sentido, no Livro I das Partes dos Animais, Aristótelesargumenta:

Visto que o corpo é um instrumento (pois cada uma das partes é em vista de algo, e semelhantemente também o todo), é necessário que ele seja de tal e tal 
qualidade e a partir de itens deste e daquele tipo, se há de ser aquilo². (ARISTÓTELES, Partes dos Animais, I.1, 642ª10-13)

Consideremos o osso (ostoun) como exemplo. Os ossos tem como funções, (i) através de suas articulações, juntamente com a carne a eles anexada por meio de ligaduras leves e fibrosas, fazer possível a flexão do corpo, e (ii) proteger os órgãos internos, como, por exemplo, as costelas (pleuraí) que envolvem o peito (stêthos), ao servir de proteção às vísceras (splánchna) em torno do coração (kardía) (ARISTÓTELES, Partes dos Animais, II.9, 654b27$\left.655^{\mathrm{a}} 2\right)^{3}$. Estas atribuições do osso são, justamente, aquilo "em vista de quê" (tò hou héneka) ele vem a ser o que é, sendo ao mesmo tempo o seu acabamento (télos) intrínseco, o qual corresponde a sua ousia (essência), pela qual o definimos. Deste modo, identificado o que o osso é, através de suas funções, assume-se essas operações próprias como hipótese, ou seja, como fundamente anterior a partir do qual se determina as consequências necessárias à efetivação de tais funções: havendo tais atribuições orgânicas, então é necessário que o osso instrumento natural apropriado a possibilitar a flexão do corpo, e proteger os órgãos internos apresente certo tamanho e configuração, e que seja composto por um material caracterizado por certa dureza e solidez (ARISTÓTELES, Partes dos Animais, II.9, 655 11-12).

A necessidade sob hipótese está, portanto, vinculada a uma concepção teleológica, na qual o acabamento intrínseco de cada parte orgânica, e do organismo como um todo, é considerado como razão suficiente para se delimitar as condições materiais necessárias à sua realização(ANGIONI, L., 1999, pp. 88-89). Este esquema de explicação se apresenta como um modelo adequado ao exame dos seres vivos porque, por exemplo, no processo de constituição do osso, a causalidade de tipo formal-final atua sobre a causalidade material-eficiente da matéria elementar, de modo que a necessidade absoluta, proveniente das propriedades essenciais dos elementos, vem a ser incluída e subsumida pela necessidade hipotética, ao conduzir a produção de determinada composição terrosa, isto é, composição na qual predomina certa proporção do elemento terra, a qual comporta aquelas propriedades que caracterizam o osso, como certo grau de dureza e solidez. Se não houvesse um fator teleológico, ou seja, a forma do animal, operando sobre as interações casuais dos elementos, seria impossível explicar como, no desenvolvimento embrionário, forma-se com regularidade determinada composição

\footnotetext{
${ }^{2}$ Com relação às citações das obras de Aristóteles traduzidas para o português, utilizei a edição "Bekker I", as traduções para o inglês das edições bilíngues da "Loeb Classical Library", as traduções para o espanhol das edições "Gredos", e a tradução para o português de L. Angioni do Livro I das Partes dos Animais.

${ }^{3}$ Aristóteles explica que não há ossos na região do ventre (koilía/gastér) em todos os animais porque, se houvesse, impediria "o inchaço que se produz necessariamente neles após a ingestão dos alimentos, e, nas fêmeas, o crescimento dos embriões" (ARISTÓTELES, Partes dos Animais, II.9, 65522-5).
} 
terrosa que corresponde à estrutura óssea (ARISTÓTELES, Partes dos Animais, III.2, 663b2930), e porque tal estrutura, no mais das vezes, ocupa similares posições em diversos organismos, dadas as ilimitadas possibilidades que podem resultar de um eventoespontâneo ${ }^{4}$.

\title{
Necessidade absoluta
}

Aristóteles reconhece que há dois tipos de causalidade envolvidos nos processos orgânicos (ARISTÓTELES, Partes dos Animais, I.1, 639b11-12; 642a 1; 642 13): (i) a causalidade formal-final, vinculada a necessidade hipotética da teleologia, e (ii) a causalidade material-eficiente, associada a necessidade sem mais, ou absoluta, embora seja concedida uma primazia explanatória à causalidade de tipo (i) em relação à de tipo (ii), pois, na constituição do organismo, acontece de a primeira incluir e subsumir a segunda. Mas, isto não significa que algumas partes não possam estar presentes no animal, estritamente, por uma necessidade absoluta, sem que haja qualquer fator teleológico operando (LENNOX, J. G., 2001a, p. 150). Por exemplo, no Livro IV das Partes dos Animais, Aristóteles dizque:

\begin{abstract}
A bílis do fígado é um resíduo e não tem nenhum fim, como o depósito [hypóstasis] que se forma no estômago e nos intestinos. Algumas vezes, certamente, a natureza utiliza também os resíduos para algo útil, mas não por isso há que buscar sempre o para quê, senão que, ao ser assim tais coisas, outras muitas sucedem por necessidade. (ARISTÓTELES, Partes dos Animais, IV.2, 677ª14-19)
\end{abstract}

Aristóteles estabelece uma distinção entre o (i) resíduo útil e o (ii) resíduo inútil. O primeiro diz respeito ao sangue, ao esperma, ao mênstruo e ao leite, já o segundo, aos excrementos, mas também inclui-se nessa categoria, pelo que se pode depreender da passagem acima citada, a bílis (cholé) do fígado (hêpar $)^{5}$. Contudo, a diferença fundamental que existe entre o excremento e a bílis como resíduos inúteis é que, por um lado, o excremento é produzido a fim de que seja eliminada a porção do alimento líquido ou sólido não aproveitado pelo organismo, e, por outro, a bílis é produzida pela vesícula biliar por mera necessidade, quando

\footnotetext{
${ }^{4}$ Como James G. Lennox argumenta, na constituição orgânica "a necessidade da natureza necessária é subordinada a uma hierarquia de fins. É a natureza formal de um animal que determina a localização e a configuração estrutural do material. [...] A natureza material, por si própria, não dita a sua locação, estrutura, ou função" (LENNOX, J. G., 2001b, p. 193).

${ }^{5} \mathrm{Na}$ Geração dos Animais, Aristóteles estabelece a seguinte distinção: "Todo resíduo provém do alimento inútil, ou do alimento útil. Chamo inútil ao que não contribui em nada para o organismo natural, mas que, consumido em excesso, é muito prejudicial; e útil, o contrário" (ARISTÓTELES, Geração dos Animais, I.18, 725a4-7). Assim, o resíduo inútil é aquele proveniente do alimento inútil, e o resíduo útil, evidentemente, do alimento útil; por exemplo, após algumas poucas linhas desta passagem da Geração dos Animais, Aristóteles diz: "o esperma é uma parte do resíduo útil" (cf. 725ª11-12).
} 
o fígado está composto por um sangue menos puro, sem qualquer finalidade envolvida (ARISTÓTELES, Partes dos Animais, IV.2, 677²5-30). Sendo assim, o estudioso da natureza deve levar em conta, na investigação, tanto a necessidade hipotética da teleologia, quanto à necessidadeabsoluta.

Para cada tipo diversificado de animais, há disponível uma proporção limitada entre os elementos materiais, a partir dos quais a forma do animal opera na formação das partes do organismo, de modo que essa limitação restringe ou constrange a atuação da natureza formal. Assim, como Lennox alega (LENNOX, J. G., 2001c, p. 195), seria por esta razão que Aristóteles declara que "a natureza não faz nada em vão, mas sempre o melhor possível para a essência de cada espécie [ou gênero] animal" (he phýsis outhèn poiei máten, all'aeì ex ton endekhoménon tei ousíai perì hékaston génos zóiou tò áriston)" (ARISTÓTELES, Progressão dos Animais, 704b15-17). Ao afirmar isto, Aristóteles levaria em consideração o fato de que há uma precondição restritiva, na qual a natureza formal agiria de acordo com os limites impostos pela naturezamaterial.

Por exemplo, em uma passagem do Livro III das Partes dos Animais, Aristóteles explica que os ovíparos (oiotóka) não possuem epiglote (epigottís) porque:

Sua carne é seca e sua pele dura, de modo que esta parte não teria boa mobilidade constituída por tal tipo de carne e pele, mas a contração dos extremos da própria traquéia seria mais rápida que a da epiglote, que tem os animais com pelo, ao estar formada por uma carne tão particular. (ARISTÓTELES, Partes dos Animais, III.3, 665ª̂n

A presença da epiglote em alguns animais é explicada no sentido de que a natureza formal, ao concebê-la, tem remediado certa inadequação referente à posição da traquéia (artería) (ARISTÓTELES, Partes dos Animais, III.3, 664b20-23; 665 8-10), localizada diante do esôfago (oisophágon) (ARISTÓTELES, Partes dos Animais, III.3, 664b2-3), de modo que, ao se fechar durante a deglutição, a epiglote impede que o alimento entre pela traquéia, mas, ao se abrir, permite a entrada e saída de ar (ARISTÓTELES, Partes dos Animais, III.3, 664b28$30)^{6}$. É a função da epiglote, portanto, que explica a sua presença em alguns animais. Contudo, apesar de, por exemplo, a traquéia das aves estar localizada junto ao esôfago, esses animais, não obstante, são desprovidos de epiglote. A razão disto consiste no fato de que, segundo Aristóteles, a carne e a pele das aves seria, respectivamente, seca e dura, sendo que uma epiglote

\footnotetext{
${ }^{6}$ Há um movimento cadenciado no qual a epiglote permanece aberta durante a respiração, mas se fecha, quando o alimento é deglutido. Às vezes, pode acontecer de o alimento ser ingerido durante a respiração, provocando tosse e sufocação (ARISTÓTELES, Partes dos Animais, III.3, 664b30-36).
} 
constituída por tais materiais não poderia desempenhar a sua função de um modo apropriado, por não possibilitar uma boa mobilidade (ARISTÓTELES, Partes dos Animais, III.3, 665²-4). No entanto, a função que a epiglote desempenharia é cumprida pela própria traquéia, ao se contrair por ocasião da ingestão dealimentos.

\title{
Necessidade hipotética e absoluta
}

A partir do exemplo acima, nota-se que a ausência de determinado componente orgânico, isto é, no caso referido, a epiglote nas aves, é explicada pela falta de um material adequado, o qual seria capaz de servir como condição necessária, sob a hipótese de haver certa estrutura apta a realizar aquela função cumprida pela epiglote, nos animais que "têm pulmões e pele coberta de pêlos" (ARISTÓTELES, Partes dos Animais, III.3, 664b23-24), mediante a atuação da natureza formal. Dado que este material não está presente nas aves, a natureza, então, faz sempre o melhor possível para a essência de cada espécie ou gênero animal, concedendo à traquéia o papel que a epiglote desempenharia nos animais que a têm. De acordo com isto, James Lennox escreve o seguinte:

\begin{abstract}
A localização da traquéia atrás do esôfago explica a necessidade, para todos aqueles que respiram ${ }^{7}$, de serem capazes de fechar a traquéia enquanto se alimentam. Mas, este requisito funcional é realizado por dois mecanismos diferentes, em duas classes distintas. As características básicas que explicam a presença ou ausência de uma epiglote em particular são as diferentes naturezas materiais da carne e da pele, nestas duasclasses. (LENNOX, J. G., 2001c, p. 198)
\end{abstract}

\footnotetext{
${ }^{7}$ De acordo com Aristóteles, os peixes não respiram. Com efeito, Anaxágoras de Clazômenas (500-428 a.C.) e Diógenes de Sínope (404 ou 412-323 a.C) são alvos de críticas por parte de Aristóteles, porque eles teriam defendido a tese de que todos os animais respiram, inclusive, os peixes. Por um lado, o primeiro, argumenta Aristóteles, "assegura que os peixes, quando expulsam a água pelas brânquias, respiram ao tomar o ar que é produzido na boca, visto que não há vazio algum"; por outro, o segundo "sustenta que, quando expulsam a água pelas brânquias, tomam ar da água que rodeia a sua boca, graças ao vazio que se produz nela" (ARISTÓTELES, Parva Naturalia, 470b31-471 5). Aristóteles, no entanto, considera isto impossível, pois quando os animais respiram "é preciso que espirem de novo pelo mesmo lugar que inspiraram, e que o façam, alternativamente, de um modo contínuo". Contudo, quando os peixes expulsam a água, "espiram pela boca ou pelas brânquias, de sorte que ocorre que espiram e inspiram ao mesmo tempo [...]. Mas, é impossível inspirar e espirar ao mesmo tempo, de sorte que é preciso que os seres que respiram espirem e inspirem e, como nenhum deles pode espirar, é evidente que tampouco nenhum deles respira" (ARISTÓTELES, Parva Naturalia, $471^{\mathrm{a}} 10$ e ss.). A função desempenhada pelo pulmão nos animais sanguíneos, a saber, refrigerar o calor do corpo por meio da respiração (ARISTÓTELES, Partes dos Animais, III.6, 668b33-669ª), é desempenhada, nos peixes, pelas brânquias (bránchia). Enquanto "o pulmão tem como fim a refrigeração pelo ar", as "brânquias têm como fim a refrigeração pela água” (ARISTÓTELES, Parva Naturalia, 476 7-11). Com relação aos cetáceos (kéte), como as baleias (phálainai) e os golfinhos (delphines), Aristóteles reconheceu que eles são desprovidos de brânquias, mas têm certa fossa nasal, denominada pneúmona, porque possuem pulmões (ARISTÓTELES, Parte dos Animais, IV.13, 697ª15-19). Segundo Sánchez-Escariche e Miguel, a respiração pulmonar dos cetáceos foi "realmente um grande descobrimento aristotélico", chamando a atenção para o fato de que Linneo, "nas dez primeiras edições (de um total de doze) de seu Systema Naturae, classificou esses animais entre os peixes" (cf. SÁNCHES-ESCARICHE E. J. e MIGUEL, A. A., 2000, p.245, nota 161).
} 
Passagens como estas sobre a presença ou ausência da epiglote, Lennox acrescenta, fornecem novos insights com relação à tese de que o estudioso da natureza deve levar em conta tanto a matéria, como a forma na investigação: ele deve estudar a matéria para poder compreender porque determinada parte homogênea, como a carne, por exemplo, tendo como alicerce os quatro elementos, é constituída por certo tipo de material, com tais e tais propriedades, visto que, dependendo do material, essa parte somente poderá ser assimilada na formação desta ou daquela parte não homogênea (por exemplo, o coração, ou a mão) pela forma do animal, a qual requer certas propriedades para o desempenho de dada função (LENNOX J. G., 2001c, p. 198-199).

Aristóteles conclui o primeiro capítulo do Livro das Partes dos Animais, com um exemplo, não muito claro, sobre o modo adequado pelo qualo estudioso da natureza deve proceder à exposiçãoinvestigativa:

Devemos expor assim deste modo: a respiração, por exemplo, é em vista disso, mas isto vem a ser a partir destes fatos por necessidade. $\mathrm{E}$ a necessidade, às vezes significa que, se há de ser aquilo em vista de que, é necessário que ele comporte estas coisas; mas às vezes significa que se comporta e é naturalmente assim. Pois é necessário que o quente saia e novamente entre ao encontrar resistência, e que o ar flua para dentro. E isto já é necessário. E na medida em que o quente interno oferece impedimento, a entrada e a saída residem no esfriamento do ar de fora. (ARISTÓTELES, Partes dos Animais, $\left.1999,642^{a} 31-642 b 2\right)$

Aristóteles procura mostrar, com este exemplo, que a respiração ocorre de acordo com (i) a necessidade absoluta da matéria elementar, e com (ii) as condições necessárias pelas quais ela vem a ser certo "em vista de quê”. Na medida em que esquenta, em função do calor corporal, o ar, através de um processo absolutamente necessário, expande e flui, via o canal respiratório, para o exterior. No entanto, ao se chocar com o ar externo, que é frio, o ar quente recua novamente ao interior do organismo. Assim, o calor do corpo resiste à entrada de ar frio do ambiente externo, de modo a fazer com que o ar quente recue ainda mais. Então, o ciclo se repete: o ar torna- sequentenointeriordocorpo,expandindo-seatravésdasviasrespiratórias,atése chocar com o ar frio do ambiente externo, e assim sucessivamente (BALME, D. M., 2001, p. 101), a fim de que o corpo estabeleça um equilíbrio térmico ${ }^{8}$.

\footnotetext{
${ }^{8}$ Como observou Balme, esta explicação relativa à respiração não corresponde àquela fornecida em $480^{\mathrm{a}} 16$ 480b12. Isto porque "Aristóteles frequentemente faz uso de exemplos tomados não de suas próprias teorias, mas de crenças comuns, e este [sc. exemplo] pode ter sido uma ortodoxia médica corrente" ( BALME, D. M., 2001, p. 101). A explicação de Aristóteles sobre o processo respiratório, na passagem referida por Balme, de um modo
} 
Os movimentos absolutamente necessários do ar, decorrentes de suas propriedades essenciais, são aproveitados pelo animal, ajustando-os a certa função orgânica, conduzida pelo processo respiratório, de modo que a necessidade desses movimentos, no organismo vivo, ocorre, também, sob hipótese, isto é, sob o pressuposto de haver determinado equilíbrio térmico-corporal, contribuindo com isso como diríamos hoje em dia, para a manutenção da estabilidade fisiológica. Deste modo, a necessidade absoluta da matéria elementar é inserida pela necessidade hipotética da teleologia, como um item integrante e indispensável a sua realização.

\section{Necessidade Geométrica}

Uma vez que não cabe à ciência da natureza estudar a ciência, pois esta é uma instância epistemológica, e não ontológica, do mesmo modo, não cabe à ciência da natureza explicar os objetos da matemática, isto é, os números e as figuras geométricas, pois, tais itens são "a partir de abstração" (tà ex aphairéseos) (ARISTÓTELES, Partes dos Animais, I.1, 641b10-11)9. Isto significa, estritamente, que a ciência natural não deve se ocupar dos itens matemáticos enquanto tais, mas ela, também, não deve se restringir, como fazem a óptica, a harmônica e a astronomia, unicamente a algumas propriedades ou comportamentos que certos entes naturais apresentam $^{10}$, de modo a explicá-las através de princípios matemáticos (ARISTÓTELES, Física, II.2. 19433-12). No entanto, é lícito que determinados aspectos dos organismos vivos sejam explicados através de premissas geométricas (ANGIONI, L., 1999, p. 85).

Por exemplo, no Livro IV das Partes dos Animais, no qual Aristóteles passa ao exame dos animais não sanguíneos (ánaima), a saber, insetos (éntoma), entre os quais estão incluídos os vermes (élmins), testáceos (ostrakódermon) - moluscos com concha (konchýlion), crustáceos (malakóstraka) e cefalópodes (malákia), explica-se a quantidade de ventosas (khotyledónes) presentes nos tentáculos (plekhtánai) dos polvos (polýpodes) a partir de

resumido, sustenta que a respiração se produz em função do aumento do calor produzido pelo coração. Por um lado, ao inspirar, o animal conduz o ar frio do exterior ao pulmão, que refrigera o excesso de calor corporal; por outro, ao expirar, pela contração do pulmão, o ar quente é expelido para fora do organismo, de modo que esse "processo se produz sem cessar, durante o tempo em que o animal vive" (ARISTÓTELES, Parva Naturalia, 480a 16-480b12).

${ }^{9}$ Apesar de Aristóteles, nesta passagem de as Partes dos Animais, não fazer menção à objetos matemáticos, ele lança mão da expressão "tà ex aphairéseos", justamente, para designar esses objetos; ver: De Anima, I.1, $403 \mathrm{~b} 15$.

${ }^{10}$ A óptica somente estuda a propriedade pela qual o corpo natural é capaz de refletir a luz, a harmônica, a propriedade dos corpos de emitirem sons, e a astronomia, por sua vez, se ocupa, principalmente, das trajetórias que os corpos celestes realizam. 
premissas geométricas:

Os polvos têm duas colunas de ventosas, exceto uma espécie, que só tem uma. A causa é a largura e delgadeza de sua natureza,pois a estreiteza faz necessária uma só coluna de ventosas. E, não é pelo fato de ser melhor assim, que tenham tal característica, mas porque é necessário pelo caráter particular de sua essência. (ARISTÓTELES, Partes dos Animais, IV.9, 685b12-16)

Como Lennox assinalou, a espécie de polvo a qual Aristóteles faz referência nesta passagem corresponde àquela denominada de heledóne (LENNOX, J. G., 2001, p. 314) (provavelmente da espécie Eledone moschata) no Livro IV da História dos Animais, a qual "se caracteriza pelo comprimento dos tentáculos, e por ser o único cefalópode com uma só fileira de ventosas" (ARISTÓTELES, História dos Animais, IV.1, 525a16-18). O número de ventosas que tal espécie de polvo apresenta é determinado, exclusivamente, pelo comprimento e largura de seus tentáculos. Pelo fato de serem delgados, só é permitido ao heledóne possuir uma coluna de ventosas. Por outro lado, as demais espécies de polvos possuem duas colunas (ARISTÓTELES, História dos Animais, IV.1, 525a18-19), ao invés de uma, visto que a maior largura tentacular lhes permite que seja assim.

Com relação a esta característica específica do heledóne, Gotthelf observa que o aspecto estritamente mensurável de seus tentáculos é um fator - denominado por ele de característica dimensional (dimensional feature) - determinante à essência dessa espécie de polvo, visto que, por apresentarem medidas tentaculares de comprimento e largura relativamente delgadas, só lhe é permitido comportar uma única coluna de ventosas, distinguindo-se, portanto, das demais espécies de polvos. Deste modo, este seria o "caso de uma característica na ousia de um animal que não é nem uma função, nem uma parte"do organismo (GOTTHELF, A., 1985, p. 41). Em outras palavras, este seria um exemplo em que certa característica contribui para a essência específica de determinado animal, que não é atividade vital ou composição material.

Gotthelf prossegue a análise da passagem em questão (ARISTÓTELES, Partes dos Animais, IV.9, 685b12-16), acima citada, dizendo que Aristóteles não sustenta, simplesmente, que ter apenas "uma coluna de ventosas é parte da ousia desta espécie de polvo"; antes, é através de "uma consequência necessária da característica dimensional, que faz com que ele diga ser parte da ousia" do héledone, pois, "dado que a ventosa deve ter, ao menos, determinada extensão, e que os tentáculos desta espécie de polvo somente podem apresentar certa largura", então, não haveria a possibilidade de o héledone ser constituído por mais de uma única coluna de ventosas em cada tentáculo. Neste sentido, a particularidade de certa espécie animal, conclui 
Gotthelf, seria explicada não a partir da necessidade hipotética da teleologia, mas por um tipo de "necessidade geométrica" (geometricalnecessity) (GOTTHELF, A., 1985, pp. 41-42).

Outro exemplo, no qual Aristóteles envolve premissas geométricas nas explicações concernentes ao domínio do vivente, em a Marcha dos Animais, diz respeito ao motivo pelo qual as serpentes (ópheis) são desprovidas depés:

Nenhum animal sanguíneo é capaz de se mover com mais de quatro pontos de apoio.Disto segue-se, evidentemente, que, quando certos animais sanguíneos têm uma longitude desproporcional com relação ao resto do corpo, como as serpentes, não podem ter pés. De fato, estes não podem ter mais de quatro pés (pois seriam não sanguíneos), e tendo dois ou quatro, seriam quase totalmente incapazes de se moverem; nestas condições, o movimento é forçosamente lento e inútil. (ARISTÓTELES, Marcha dos Animais, 708ª-20)

De acordo com Aristóteles, "nenhum animal sanguíneo pode se mover com mais de quatro pontos de apoio" (ARISTÓTELES, Marcha dos Animais, 707²1-23). Dentre eles, inserem-se (i) os quadrúpedes (tetrápoda), com duas patas traseiras e duas patas dianteiras, e (ii) os bípedes (dípous), incluindo tanto as aves (órnithas), quanto os seres humanos (ánthropoi), com dois pontos de apoio. Por conseguinte, as serpentes, por serem animais sanguíneos, só poderiam ser providas de, no máximo, quatro patas. Porém, pelo fato do comprimento corporal da serpente apresentar uma grande diferença proporcional relativamente a sua largura, ela se locomoveria com dificuldades com apenas quatro pontos de apoio. Então, dado que, como Aristóteles frequentemente enuncia, "a natureza não faz nada em vão, senão sempre o melhor possível à essência de cada espécie animal" (ARISTÓTELES, Marcha dos Animais, 104b15-17, 708 9-12) ${ }^{11}$, as serpentes são ápodes, realizando um movimento corporal ondulatório.

O motivo pelo qual as serpentes são ápodas e, portanto, realizam um movimento ondulatório, é explicada por análises geométrico-matemáticas, ou seja, pela relação proporcional entre o comprimento e a largura, que as configurações de seus corpos comportam. Sendo assim, as serpentes, bem como a espécie de polvo héledone, representam casos nos quais “características dimensionais" - conforme expressão adotada por Gotthelf - estão envolvidas na determinação essencial de certo tipo de organismos (GOTTHELF, A., 1985, pp. 44-45).

Por estas razões, discordo de Balme quando ele escreve que "as matemáticas aplicadas

\footnotetext{
${ }^{11}$ No que se refere a outras passagens em que Aristóteles recorre à sentença "a natureza não faz nada em vão" (he phýsis outhèn poiei máten) ver, por exemplo: Partes dos Animais, II.14, 658a9; III.1, 661b23; IV. 11, 691b4; IV.12, 694a15; IV.13, 695b19; Parva Naturalia, 476a14. Sobre esta questão, ver o artigo de J. Lennox, 2001b, pp. 205-223.
} 
são inúteis na zoologia" de Aristóteles. Mas, concordo quando ele afirma que "o comportamento dos organismos naturais não pode ser reduzido à mecânica dos corpos abstraídas da natureza, uma vez que a explicação deve incluir uma tendênciateleológica" (BALME, D. M., 2001, pp. 98-99). Por um lado, é verdade que certa particularidade da espécie de polvo héledone, e das serpentes, é explicada e determinada por uma necessidade geométrica, associada a propriedades dimensionais da matéria composicional. Mas, por outro lado, o héledone, apesar de ser constituído por tentáculos delgados, e, por isso, possuir apenas uma coluna de ventosas ao invés de duas, como nas outras espécies de polvo, ele não deixa, no entanto, de apresentar tentáculos e ventosas, de modo a servirem como mãos a fim de capturar o alimento, tanto quanto órgãos de ataque e defesa (ARISTÓTELES, Partes dos Animais, IV.9, 685b4-11). As serpentes, por sua vez, são ápodas por causa da relação proporcional entre a largura e o comprimento de suas configurações corporais, mas, sendo assim, elas são capazes de desempenhar de um modo eficaz a função locomotora, através de movimentos ondulatórios. Portanto, embora possam ser admitidas premissas estritamente geométricas na explicação de algumas características de certos tipos de organismos vivos, em última instância, tais características são subsumidas, ou apropriadas, por fatoresteleológicos, em função da necessidade hipotética.

\section{Princípios Gerativos}

Os diversos arranjos composicionais, das várias espécies de animais, não vêm a se constituir espontaneamente a partir do acaso, de acordo, meramente, com uma necessidade absoluta. Neste sentido, no Livro I das Partes dos Animais, Aristóteles diz o seguinte:

Certamente, não é qualquer coisa ao acaso que vem a ser a partir de cada semente, mas, antes, é isto a partir disto, e nem sequer vem a ser uma semente qualquer ao acaso a partir de um corpo qualquer que ocorra ao acaso. Assim, portanto, a semente é princípio, e fator eficiente daquilo que vem a ser a partir dela, pois essas coisas são por natureza; em todo caso, ao menos, nascem a partir dela. Mas, inclusive é ainda anterior a ela aquilo de que ésemente. (ARISTÓTELES, Partes dos Animais, I.1, 641b26-31).

O termo semente (spérma), em Aristóteles, abrange um amplo campo semântico, sendo que tal termo não se restringe ou se reduz ao significado de esperma, ou sêmen masculino dos animais, mas, também, ao de semente das plantas, e, de um modo geral, ao de gérmen, origem ou princípio de algo ( SÁNCHEZ, E., 1994, p. 84, nota 89). Dado esta flexibilidade semântica, 
em um trecho de a Geração dos Animais (ARISTÓTELES, Geração dos Animais, I.18, 724b1218), Aristóteles estabelece uma distinção entre (i) líquido seminal (goné) e (ii) semente (spérma). O (i) líquido seminal seria aquilo "que provém do que engendra, em todos os animais que por natureza copulam”, isto é, os princípios gerativos da reprodução sexuada, os quais correspondem tanto ao resíduo menstrual da fêmea, quanto ao esperma masculino, e, a (ii) semente, aquilo “que contém os princípios de ambos os sexos que se têm unido", identificandose à "primeira mescla que se forma de uma fêmea e um macho, ou seja, uma espécie de embrião ou ovo" 12 . Portanto, em um primeiro sentido, mais particular, com relação ao processo de geração orgânica, o princípio gerativo do macho é semente (spérma), mais, num segundo sentido, mais geral, semente se refere, principalmente, àquilo que resulta da conjunção dos líquidos seminais masculino e feminino, no ato dafecundação.

Tendo em vista este segundo sentido, na passagem supracitada, Aristóteles pretende dizer que a semente não vem a ser por acaso, a partir de um corpo qualquer, mas por meio da confluência dos líquidos seminais masculino e feminino, determinada pela função reprodutiva do organismo, de modo que, através da semente, não surgiria algo qualquer ao acaso, mas, como é dito no Livro II da Física, por exemplo, da semente de oliveira provém oliveira, e da semente humana provém um ser humano (ARISTÓTELES, Física, II.4, 196331). Entretanto,sob uma perspectiva ainda mais geral,aprópriaoliveira, ou o próprioser humano, são considerados sementes, pois, como Aristóteles argumenta no Livro I das Partes dos Animais, "a semente é de dois modos: daquilo a partir de que e daquilo de que é" (ARISTÓTELES, Partes dos Animais, I.1, 641b33-34), sendo que a oliveira e o ser humano são sementes enquanto (i) “daquilo a partir de que”, isto é, enquanto princípio em relação ao qual vem a ser gerado um outro indivíduo, e, de outro modo, aquilo que resulta da união dos líquidos seminais é semente enquanto (ii) “daquilo de que é”, ou seja, enquanto origem pela qual o próprio organismo vem a serdesenvolvido.

A semente sob a perspectiva (i) é anterior tanto do ponto de vista lógico, quanto, de certo modo, do ponto de vista temporal, relativamente à semente sob a perspectiva (ii), pois, o embrião, ou a primeira mescla que se forma de uma fêmea e de um macho, sendo potencialmente determinado organismo, pressupõe a existência de um organismo desenvolvido (progenitor) para vir a ser em efetividade: a fim de que algo em potência, passe a ser efetividade,

\footnotetext{
12 Penso que esta primeira mescla, na qual se forma o que Aristóteles chama de uma espécie de embrião ou ovo, poderia ser identificada ao que hoje em dia designaríamos por zigoto, não quanto à sua estrutura orgânica (celular), mas quanto à sua função.
} 
é preciso, antes, haver aquilo que atualize essa potencialidade (ARISTÓTELES, Metafísica, IX.8, 1049b24-29). O que atualiza a potencialidade da semente embrionária é, justamente, o progenitor, o qual promove a efetividade de um novo indivíduo especificamenteidêntico.

Assim, é possível notar, em Aristóteles, uma escala crescente e circular, que parte de níveis mais particulares aos mais gerais, no que diz respeito aos princípios da formação, teleologicamente determinada, de um novo indivíduo. O primeiro nível corresponde (i) aos respectivos líquidos seminais dos progenitores, o segundo, (ii) ao que resulta da união desses líquidos no ato da concepção e, o terceiro, (iii) ao organismo plenamente desenvolvido, que atingiu a maturidade sexual, e que é capaz de produzir o princípio gerativo situado no primeiro nível da escala, isto é, o líquido seminal. Então,a partir daí, o ciclo se repete, promovendo, continuamente, a consecução de certo fim, a saber, o estado adulto do progenitor.

Este fim, a que sempre tende todos os organismos vivos, através das gerações, estabelecendo um ciclo permanente, é a razão fundamental pela qual os seres vivos se reproduzem. No início do Livro II da Geração dos Animais, Aristóteles faz a seguinte declaração:

Que o eterno é possível que exista e que não exista, e que participe do pior e do melhor; que a alma é melhor que o corpo, o animado é melhor que o inanimado por causa da alma, e o ser melhor que o não ser, e viver melhor do que não viver, por todas estas causas há geração dos animais. (ARISTÓTELES, Geração dos Animais, II.1, 731b27-32)

Quando os seres vivos atingem a maturidade e se reproduzem, lhes é possível se preservarem na existência, garantindo, com isso, a conservação na realidade entitativa, de modo a legitimar a sua substancialidade ${ }^{13}$ de caráter superior, relativamente, por exemplo, aos elementos, visto que o ser "animado é melhor que o inanimado" e, "viver melhor do que não viver".

\section{Considerações Finais}

Conforme Aristóteles, todas as coisas ou bem (i) são eternas, como os astros e as esferas celestes, ou bem (ii) pertencem ao domínio daquelas que são capazes de ser e de não ser, ou seja, das que são geradas e que perecem, como as plantas ou os animais, e , de um modo geral,

\footnotetext{
${ }^{13}$ Em a Geração e Corrupção, Aristóteles declara que "o ser pode possuir o maior grau de consistência, porque o perpétuo produzir-se da geração é aquilo que mais se aproxima da substância" (ARISTÓTELES, Geração e Corrupção, II.10, 336b32-34). Em outros termos, na medida em que o ente natural fixa raízes no ser, em meio ao processo de geração e corrupção, através do contínuo produzir-se, ele é capaz de se manter, com um maior grau de consistência, a sua legitimidade substancial.
} 
todos os seres que habitam o mundo sublunar (ARISTÓTELES, Partes dos Animais, I.5, 644b15 e ss.; BALME, D., 2001, p. 155). No entanto, seja qual for o ente natural, ele é enquanto algo particular. Por conseguinte, se o ente natural é eterno, ele será enquanto algo particular. Todavia, as coisas sujeitas ao processo de geração e corrupção não são eternas, o que significa que elas não são, estritamente, eternas em número, ou seja, nenhum indivíduo como, por exemplo, Sócrates, em suas particularidades, é eterno enquanto tal. Porém, do ponto de vista da essência de Sócrates, ou seja, do ser homem, ele o é, na medida em que a espécie humana é perpetuada através da reprodução em cada indivíduo (BALME, D. M., 2001, p. 156). No Livro II do De Anima, Aristóteles diz o seguinte:

Uma vez que são incapazes de partilhar do eterno e do divino através de uma existência ininterrupta, já que nenhum ser submetido à corrupção pode permanecer sendo o mesmo em sua individualidade, cada um participa na medida em que é possível, uns mais, outros menos; e perdura não um mesmo, senão outro indivíduo semelhante a ele, um não em número, mas emespécie. (ARISTÓTELES, De Anima, II.4, 415b3-7)

Aristóteles, neste trecho, diz que o que perdura não é o indivíduo particular, mas a espécie. É preciso, no entanto, ter cautela ao avaliar o sentido desta afirmação. Afirmar que é a espécie, e não o indivíduo, o que persiste mediante o processo reprodutivo, não significa necessariamente dizer que a espécie, enquanto indicador referencial de determinado conjunto de seres vivos, é eterna; antes, parece significar que certos organismos particulares, os quais compartilham as mesmas características essenciais, na medida em que se reproduzem, conservam-se noser.

As infindáveis variações que os diversos indivíduos de uma mesma espécie apresentam com relação à textura, matiz, temperatura, dimensão, etc. de suas constituições orgânicas, determinam as suas particularidades. Estas particularidades são, justamente, aquilo que está sujeito à geração e corrupção, e que, portanto, não é eterno. No entanto, os seres vivos, que pertencem a certo tipo específico, sempre comportam, apesar das variações de composição material, um mesmo conjunto organizado de estruturas e propriedades essenciais, transmitidas de geração a geração. Desta forma, não seria, exatamente, a espécie considerada em si mesma e por si mesma o que é eterno, mas sim os organismos especificamente idênticos - fazendo da espécie, por isso, uma unidade em meio à multiplicidade -, enquanto compartilham as mesmas características essenciais através dareprodução (LENNOX, J. G., 2001, pp. 131-159).

\section{Referências Bibliográficas}


ANGIONI, Lucas. As Partes dos Animais, Livro I. Trad. e comentários de L. Angioni. Campinas: Cadernos de História e Filosofia da Ciência, 9 (3) (n. especial), 1999.

ARISTÓTELES. Aristotelis Opera. BEKKER, I. (ed.). Berlim: Academia Regia Borussica, Vols. I-II, 1831.

Library, 1947.

The Metaphysics, Books I-IX. Trad. Hugh Tredennick. London: The Loeb Classical Generation of Animals. Trad. A. L. Peck. London: The Loeb Classical Library, 1953.

On Sophistical Refutations; On Coming-to-be and Passing Away; On the Cosmos. Trad. E. S. Foster, and D. J. Furley. London: The Loeb Classical Library, 1955.

On the Soul; Parva Naturalia, On Breath. Trad. W. S. Hett. London, The Loeb Classical Library, 1957.

Parts of Animals; Movement of Animals; Progression of Animals. Trad. A. L. Peck. London: The Loeb Classical Library, 1961.

Aristotle History of Animals, Books IV-VI. Trad. A. L. Peck. London: The Loeb Classical Library, 1970.

Investigación sobre los Animales. Trad. J. P. Bonet. Madrid: Biblioteca Clásica Gredos, 1992.

1994.

Reproduccíon de los Animales. Trad. E. Sánchez. Madrid: Biblioteca Clásica Gredos,

Acerca de la Generación y la Corrupción; Tratados Breves de Historia Natural. Trad. E. La Croce, e A. B. Pajares. Madri: Biblioteca Clásica Gredos, 1998.

As Partes dos Animais, Livro I. Trad. e comentários de L. Angioni. Campinas: Cadernos de História e Filosofia da Ciência, 9 (3) (n. especial), 1999.

. Partes de los animales; marcha de los animales; movimiento de los animales. Trad. E. J. Sánchez-Escariche y A. A. Miguel. Madrid: Biblioteca Clásica Gredos, 2000.

Física. Trad. G. R. de Echandía. Madrid: Biblioteca Clásica Gredos, 2002.

Acerca del Alma. Trad. T. C. Martínez. Madrid: Biblioteca Clásica Gredos, 2003.

Metafísica. Trad. T. C. Martínez. Madrid: Biblioteca Clásica Gredos, 2006.

BALME, David. Aristotle De Partibus Animalium I and De Geratione Animalium I: with passages from II. 1-3. Translated with notes by D. Balme. Oxford: Clarendon Press ("Clarendon Aristotle Series"), 2001.

GOTTHELF, Allan. Notes towards a Study of Substance and Essence in Aristotle's Parts of 
Animals ii- iv, In Gotthelf, A. (ed.), Aristotle on Nature and Living Things, Pittsburgh/Bristol: Mathesis publications/Bristol Classical Press, 1985, pp. $27-54$.

LENNOX, James. Aristotle: On the Parts of Animals, Books I-IV. Translated with an Introduction an Comentary by J. Lennox. Oxford: Clarendon Press, 2001a.

Nature Does Nothing in Vain..., In Aristotle's Philosophy of Biology. Cambridge: Cambridge University Press, 2001b, pp. 205-223.

Material and Formal Natures in Aristotle's De Partibu sAnimalium, In Aristotle's Philosophy of Biology. Cambridge: Cambridge University Press, 2001c, pp.182-204.

SÁNCHEZ-ESCARICHE, Elvira Jiménez y MIGUEL, Almudena Alonso. Partes de los animales; marcha de los animales; movimiento de los animales. Introducciones, traducciones y notas de E. J. Sánchez-Escariche y A. A. Miguel. Madrid: Biblioteca Clásica Gredos, 2000.

Reproduccíon de los Animales. Introducciones, traducciones y notas de E. J. Sánchez-Escariche. Madrid: Biblioteca Clásica Gredos, 1994. 